Research Article

\title{
Study on Impact Tendency of Coal and Rock Mass Based on Different Stress Paths
}

\author{
Chengliang Zhang, ${ }^{1}$ Danyong Ye, ${ }^{1}$ Ping Yang, ${ }^{2}$ Shunchuan $W u,{ }^{1}$ and Chao Wang $\mathbb{D}^{1}$ \\ ${ }^{1}$ Faculty of Land Resources Engineering, Kunming University of Science and Technology, Kunming 650093, China \\ ${ }^{2}$ Faculty of Public Security and Emergency Management, Kunming University of Science and Technology, Kunming 650093, \\ China
}

Correspondence should be addressed to Chao Wang; chaobest@163.com

Received 13 August 2020; Revised 25 October 2020; Accepted 4 November 2020; Published 29 November 2020

Academic Editor: Fengqiang Gong

Copyright (C) 2020 Chengliang Zhang et al. This is an open access article distributed under the Creative Commons Attribution License, which permits unrestricted use, distribution, and reproduction in any medium, provided the original work is properly cited.

\begin{abstract}
With the increased mining depth, the dynamic disaster of rock burst in coal mines has become increasingly prominent, and the impact tendency of coal and rock mass in deep coal seam mining is a necessary condition for the occurrence of rock burst and an important index to measure the failure of coal and rock mass. Laboratory tests and numerical tests were used to study the impact tendency of coal and roof strata, including the deformation characteristics, failure characteristics, and bending energy index of the coal and rock mass of different sizes, the failure law and energy evolution characteristics of the coal and rock mass under the same size, and the unloading characteristics of the coal and rock mass under the same size and different confining pressures. The results are shown as follows: (1) The rock roof was determined to have a weak impact tendency through the mechanical test. (2) With the increased size, the microcracks in the rock samples increased correspondingly, and the increased meso-defect leading to the increased heterogeneity was an essential reason for the size effect. The strength of the rock mass decreased with the increased specimen size. The larger the specimen size was, the lower the bending energy index was. (3) Triaxial loading and unloading were tested for the same size under different surrounding rocks. Under the same loading conditions, with the increased confining pressure, the strength and bending energy index of rock mass increased correspondingly, and the failure of rock mass transformed from tensile to shear failure. The failure form and strength characteristic of rock under the unloading condition are different from those under the loading condition. The failure degree was intense, with a high bending energy index. Compared with the loading situation, the impact tendency caused by unloading was higher, and the dynamic impact disaster was more likely to occur.
\end{abstract}

\section{Introduction}

Rock burst, a common dynamic disaster often accompanied with sudden, quick, and violent ejection of coal or rock during the exploitation of the coal seams, often happens in complex ways under special conditions, even without warning signs $[1,2]$. Such a failure characteristic poses a great threat to the safety and efficiency of mining $[3,4]$. The mining depths have exceeded $800 \mathrm{~m}$ in Northeast, East, and Central China and other regions. Besides, some mines have reached more than $1,000 \mathrm{~m}$ [5]. Different from shallow mining, the nonlinear mechanical behaviour of deep rock mass is complicated, and the deformation of rock mass has brittle-ductile transformation, rheological properties, and expansion properties [6]. At the same time, with the increased mining depth, coal mine rock burst and other dynamic disasters have become increasingly prominent [7]. Rock burst mines have increased from 142 in 2012 to 177 in 2017 [8], which leads to collapse, equipment damage, and even casualties. It poses a severe threat to mine production and personnel security.

As one of the main disasters of deep mining, rock burst has been widely concerned. Studies have shown that the occurrence of rock bursts is usually closely related to factors such as the impact tendency of coal and rock [9], the occurrence environment and structural characteristics of coal and rock mass properties of the surrounding rock, and engineering blasting and mining disturbance [10]. As a 
necessary condition for the occurrence of rock burst, the impact tendency is not only an index to measure the impact failure but also an inherent mechanical property [11]. Despite decades of research studies, some aspects still need to be improved and its control remains a critical research point [12]. Su et al. [13] put forward three new indexes considering the time effect, which are combined with the traditional four impact tendency indexes to improve the accuracy and reliability of rock burst. Ma et al. [14] studied the brittleness coefficient of the impact tendency of coal and rock. Dou et al. [15] proposed that coal-rock sample proportions have an apparent influence on the impact tendency index. Based on theoretical analysis and experimental measurement, Yao et al. [16] classified the impact tendency indexes of coal samples by taking surplus energy and peak damage factor as a judgment basis. Lu et al. [17] used the test system of rock servo rigidity to determine the impact tendency index with different bedding angles. Gong et al. [18] studied that the critical loading rate has a significant influence on the impact tendency of coal-rock assembly. Wang et al. [19] established a Bayes discriminant model to classify the impact tendency of coal samples from ten coal mines.

The work studied the impact tendency of the coal seam and roof strata using the mechanical test and numerical simulation methods. First of all, the mechanical parameters were obtained through laboratory mechanical experiments, with the impact tendency index of coal and rock mass calculated and the impact tendency of roof strata classified. Secondly, the rock failure process analysis (RFPA) model was constructed by mechanical parameters to analyze the failure characteristics, size effects, and energy evolution laws of rock masses under different sizes, different confining pressures, and different stress paths. Additionally, we analyzed the reliability of the classification and discrimination results, which was used to predict and forecast rock bursts. The data basis is provided, which has a useful reference for preventing the impact tendency of the coal seam roof.

\section{Specimen Preparation and Testing}

2.1. SamplingLocation. A coal mine is a medium-sized mine with an annual output of 900,000 tons. The mining depth of the main coal seam reaches more than $500 \mathrm{~m}$, with shaft development adopted. The main mining coal seam is located at 1,210 level and is a thick coal seam with a thickness of $3.15-6.80 \mathrm{~m}$ and an average thickness of $4.20 \mathrm{~m}$. Rock burst accidents have occurred many times during mining, which has a particular impact tendency. The roof of the coal seam is argillaceous sandstone and silty sandstone. The thickness of argillaceous sandstone is $2.32-23.75 \mathrm{~m}$; the average thickness is $18.35 \mathrm{~m}$; the thickness of silty sandstone is $3.85-29.20 \mathrm{~m}$; and the average thickness is $16.85 \mathrm{~m}$. To determine the impact tendency of the main mining coal seam, it is necessary to test the mechanical properties of the coal and roof rock mass, and the sampling location is 1,210 level. The test items are as follows: apparent density, elastic modulus, tensile strength, and compressive strength of rock samples. According to the test results, the impact tendency of coal and rock strata was classified to determine that of the roof rock strata. Figure 1 shows its sampling location.

2.2. Specimen Preparation. To carry out experimental studies on the impact tendency of coal and rock mass under uniaxial compression, coal, argillaceous sandstone, and silty sandstone were chosen for this study. The experimental studies involve circular and disk specimens, whose corresponding sizes are $50 \mathrm{~mm}$ diameter $\times 100 \mathrm{~mm}$ height and $25 \mathrm{~mm}$ thickness $\times 50 \mathrm{~mm}$ diameter, respectively [20]. These specimens were cut from a block of argillaceous sandstone, coal, and silty sandstone. The processing precision of these rocks was according to the requirements of ISRM. The preparation process of rock is illustrated in Figure 2. The rock number is illustrated in Table 1, and a total of 36 rock samples were processed in this experiment, with 12 in each group.

2.3. Test Scheme. To systematically study the impact tendency and mechanical behaviour of coal and rock mass, both cylindrical and disk specimens were made. The uniaxial compression test was performed on cylindrical specimens to measure the elastic modulus, and the Brazilian test was performed on disk specimens to measure the tensile strength. For the convenience of testing, the cylindrical rock was used to test the basic physical and mechanical parameters; therefore, six rock samples were used for each test parameter.

2.4. Test Equipment and Procedure. These tests were conducted using an RLJW-2000 servo-controlled rock pressure testing machine at Faculty of Land Resources Engineering, Kunming University of Science and Technology. The maximum loading capacity and axial displacement were $2000 \mathrm{kN}$ and $100 \mathrm{~mm}$, respectively, with an accuracy of $\pm 1 \%$. The testing system includes a loading control system, PCI-2 AE monitoring system, and DSCM system, as shown in Figure 2. The loading rate was $0.25 \mathrm{~mm} / \mathrm{min}$. DSCM, a particle-tracking method that uses digital images to evaluate the full-field displacement, was used to measure the deformation characteristics before the peak stress. The CCD camera was positioned parallel to the surface of the specimen. An AE monitoring system with an $\mathrm{A} / \mathrm{D}$ resolution of 18 bits and a signal-noise ratio of less than $60 \mathrm{~dB}$ was applied to record the AE signals. The preamplifier and threshold values were set to $40 \mathrm{~dB}$ and $50 \mathrm{~dB}$, respectively. Vaseline was used to improve the coupling between the sensor and the specimen. The load in the Brazilian tests was applied with curved jaws.

The apparent density was measured by the volume product method [21]. The electronic balance was used to weigh with an accuracy of $0.01 \mathrm{~g}$, and the average value was calculated after three measurements. The vernier caliper was used to measure the diameters of the three cross-sections at the two ends and the middle of the test sample with an accuracy of $0.01 \mathrm{~mm}$. The average value was taken to calculate the cross-sectional area. Furthermore, the vernier 


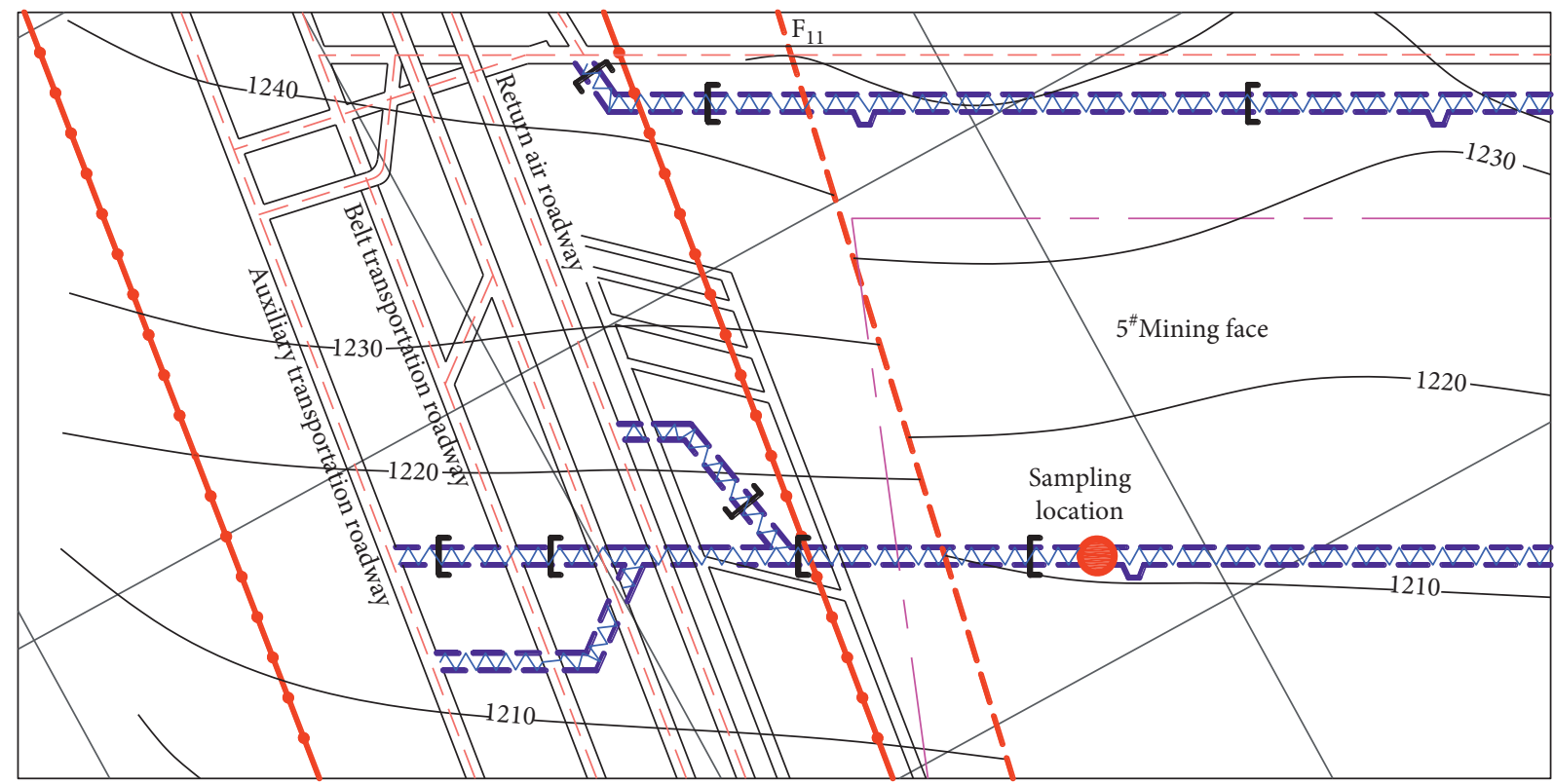

Figure 1: Schematic diagram of sampling location.
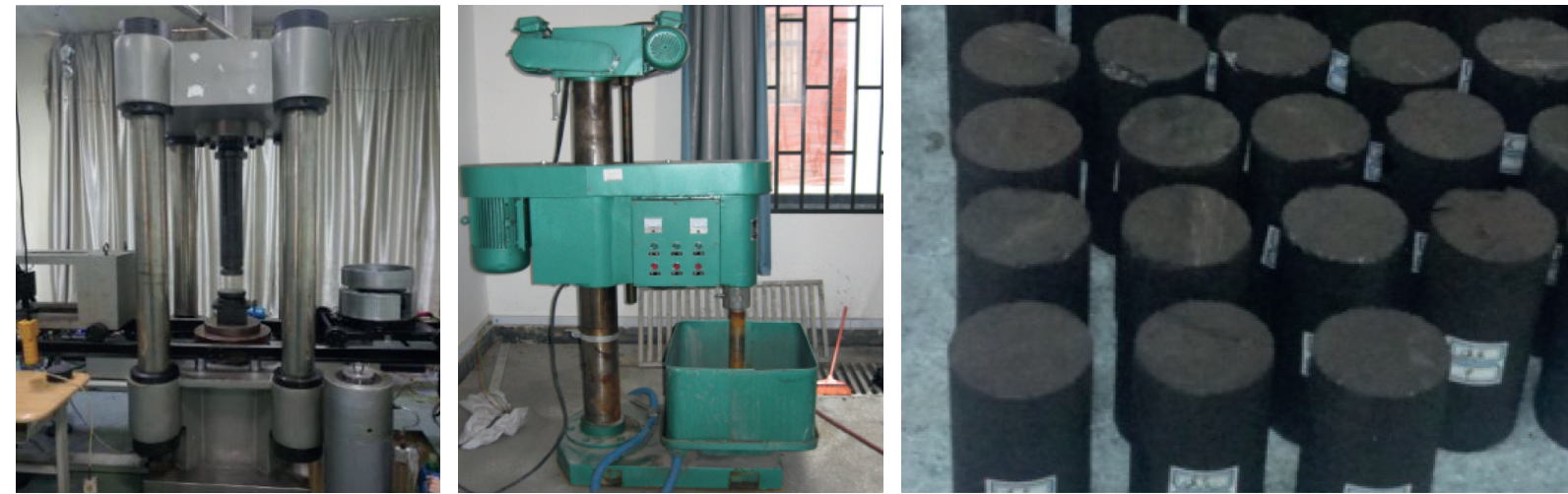

FIGURE 2: Sketch of the preparation of argillaceous sandstone, coal, and silty sandstone.

TABLE 1: Sampling quantity of coal seam and roof rock mass.

\begin{tabular}{lcc}
\hline Lithology & Layer thickness $(\mathrm{m})$ & Number \\
\hline Argillaceous sandstone & 18.35 & 12 \\
Coal & 4.20 & 12 \\
Silty sandstone & 16.85 & 12 \\
\hline
\end{tabular}

caliper was used to measure the height of three points around the end surface with an accuracy of $0.01 \mathrm{~mm}$. Finally, the average height was calculated according to the rock mechanics test method, and the number of samples involved in the calculation is six.

The uniaxial compression test was performed by using a rock servo pressure testing machine. The specimen was placed in the center of the pressure plate of the test machine and made the both ends of the specimen contact evenly by adjusting the spherical base. The loading rate was $0.5 \mathrm{MPa} / \mathrm{s}$, the load and deformation were measured, the failure loads were recorded, and the elastic modulus was obtained by pressing the formula [22]:

$$
E=\frac{\sigma_{b}-\sigma_{a}}{\varepsilon_{b}-\varepsilon_{a}}
$$

where $E$ is the elastic modulus, $\sigma_{a}$ is the stress value at the beginning point of a straight line section on the stresslongitudinal strain curve, $\sigma_{b}$ is the stress at the end of a straight line, $\varepsilon_{a}$ is the longitudinal strain stress under stress of $\sigma_{a}$, and $\varepsilon_{b}$ is the longitudinal strain stress under stress of $\sigma_{b}$.

The tensile strength was measured by the indirect tensile method (the Brazilian splitting method), and the loading rate was $0.03-0.05 \mathrm{MPa} / \mathrm{s}$, and the failure load was recorded.

\section{Mechanical Behaviour of Specimens under Uniaxial Compression}

In this test, basic physical and mechanical tests were performed, and twelve rock samples were taken from each rock layer for testing. Table 2 shows the test results of apparent density. Mechanical tests were carried out, and six rock 
Table 2: Apparent density of coal seam and rock roof samples.

\begin{tabular}{|c|c|c|c|c|c|c|c|}
\hline \multirow{2}{*}{ Rock stratum } & \multicolumn{6}{|c|}{ Serial number } & \multirow{2}{*}{ Average apparent density $\left(\mathrm{g} / \mathrm{cm}^{3}\right)$} \\
\hline & 1 & 2 & 3 & 4 & 5 & 6 & \\
\hline Argillaceous sandstone & 2.38 & 2.33 & 2.35 & 2.37 & 2.32 & 2.36 & 2.35 \\
\hline Coal & 1.39 & 1.38 & 1.45 & 1.43 & 1.45 & 1.42 & 1.42 \\
\hline Silty sandstone & 2.26 & 2.25 & 2.31 & 2.27 & 2.26 & 2.28 & 2.27 \\
\hline
\end{tabular}

samples were taken from each layer for the uniaxial compression test. Figure 3 shows the uniaxial compression curves, and Table 3 shows the test results of the elastic modulus. Six rock samples were taken from each rock layer to test the tensile strength. Figure 4 shows the Brazilian splitting test curves, and Table 4 shows the test of the coal seam and roof rock mass.

\section{Standard and Classification of Impact Tendency}

The impact tendency index is expressed by the bending energy index $\left(U_{W Q S}\right)$; the bending energy index of a single roof is calculated according to the following formula:

$$
U_{W Q}=102.6 \frac{\left(S_{t}\right)^{5 / 2} h^{2}}{E q^{1 / 2}}
$$

where $U_{W Q}$ is the single roof bending energy index, $S_{t}$ is the tensile strength, $h$ is the single roof thickness, $E$ is the elastic modulus, and $q$ is the vertical stress generated by overlying strata stress.

$$
q=\rho H g \times 10.6
$$

where $H$ is the distance, $\rho$ is the apparent density, and $g$ is the gravitational acceleration.

By substituting equation (3) into equation (2), the bending energy index of composite roof rock strata can be obtained:

$$
U_{W Q S}=\sum_{i=1}^{n} U_{W Q i},
$$

where $U_{W Q S}$ is the bending energy index of the composite roof, $U_{W Q i}$ is the bending energy index, and $n$ is the number of the roof layer. Table 5 shows the rock impact tendency [23].

The bending energy index and the impact tendency category are calculated according to formula (4); the bending energy indices are listed in Table 6.

According to the measured data and calculation, the single rock roof bending energy indexes of the three rock layers of argillaceous sandstone, coal, and silty sandstone are $18.35 \mathrm{~kJ}, 1.19 \mathrm{~kJ}$, and $21.20 \mathrm{~kJ}$, respectively. The argillaceous sandstone and silty sandstone belong to type II and have a particular impact tendency. In contrast, the coal seam belongs to class I and has no impact tendency. The bending energy index of the composite roof is $40.74 \mathrm{~kJ}$, which also belongs to type II, indicating that the whole roof strata have a weak impact tendency. According to the phenomenon of the dynamic disaster of the coal and rock mass occurred many times in the process of mining coal seam and roof management, the inherent law of rock mass failure will be revealed by numerical simulation to explore the mechanism of rock burst and reveal the evolution process of the dynamic disaster of coal and rock mass.

\section{Mechanical Behaviour of Rock Mass with Numerical Test}

5.1. RFPA ${ }^{2 D}$ Software Function. RFPA is developed by the Center for Rock Fracture and Instability of Northeastern University, which is to simulate rock failure from mesodamage to macrodamage based on finite element theory $[24,25]$. Based on the elastic damage theory, the material medium model is discretized into a material model composed of mesoscopic basic elements, and the stress calculation and phase transformation analysis are independent of each other. [26]. At present, it is widely used to study the fracture process and acoustic emission characteristics of the nonuniform rock mass, such as slope sliding, roadway instability, roof caving, rock burst, gas outburst, and so on [27]. In this test, $\mathrm{RFPA}^{2 \mathrm{D}}$ software was used to simulate the characteristics of the rock mass failure process under different sizes, surrounding pressure, and stress paths. Furthermore, the evolution laws of rock mass failure generating dynamic disasters were revealed.

5.2. Numerical Simulation Scheme. To systematically study the mechanical behaviour of rock mass, (1) the failure characteristics of rock mass is to be analyzed under different sizes used by uniaxial compression, whose corresponding cylindrical sizes are $50 \mathrm{~mm} \times 100 \mathrm{~mm}, \quad 75 \mathrm{~mm} \times 150 \mathrm{~mm}, \quad 100 \mathrm{~mm} \times 200 \mathrm{~mm}$, $150 \mathrm{~mm} \times 300 \mathrm{~mm}$, and $200 \mathrm{~mm} \times 400 \mathrm{~mm}$, and the strength variation law and failure characteristics were analyzed; (2) the failure characteristic is to be analyzed under the same size and different confining pressures, the triaxial compression of $50 \mathrm{~mm} \times 100 \mathrm{~mm}$ was carried out, and the confining pressures are 10, 20, 30, 40, and $50 \mathrm{MPa}$; and (3) triaxial unloading failure is to be analyzed under different confining pressures, the triaxial unloading test of $50 \mathrm{~mm} \times 100 \mathrm{~mm}$ was carried out, and the failure characteristic is to be analyzed during the process of unloading, with the confining pressures of $10,20,30,40$, and $50 \mathrm{MPa}$

5.3. Physical and Mechanical Parameters of Numerical Test. The mechanical parameters were taken from the values measured in the laboratory. The internal friction angle was $35.5^{\circ}$, with the elastic modulus of $9.85 \mathrm{GPa}$, the compression tension ratio of 10 , the tension coefficient of 1.5 , Poisson's 


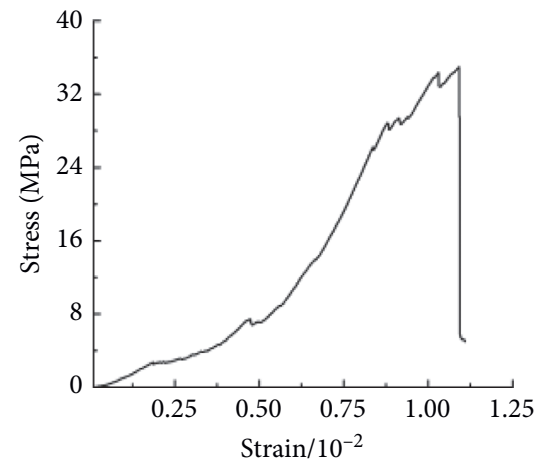

(a)

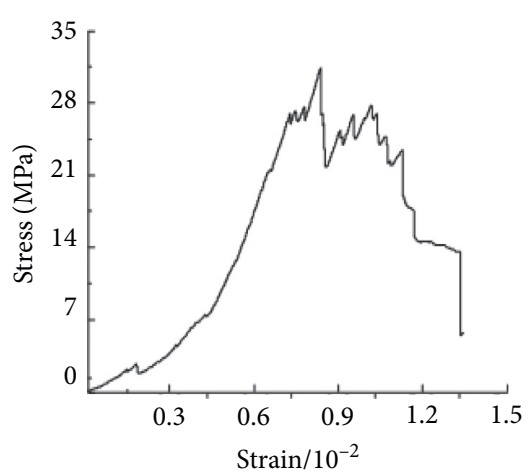

(b)

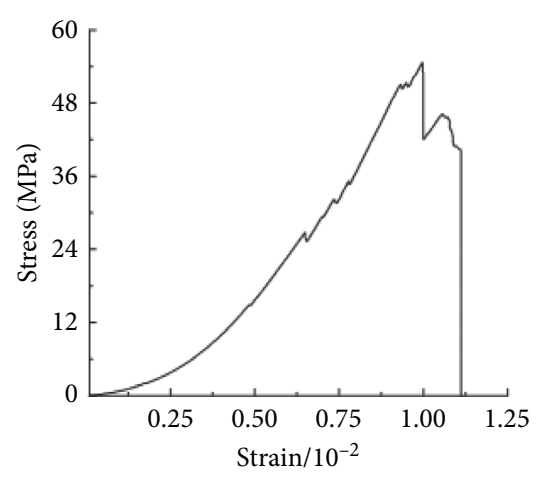

(c)

FIgURE 3: Typical stress-strain curves of samples: (a) argillaceous sandstone, (b) coal, and (c) silty sandstone.

TABLE 3: Test of the elastic modulus of coal seam and roof rock samples.

\begin{tabular}{lccccccc}
\hline \multirow{2}{*}{ Rock stratum } & \multicolumn{9}{c}{ Serial number } & \multicolumn{2}{c}{ Average elastic modulus (GPa) } \\
& 1 & 2 & 3 & 4 & 5 & 6 & 9.88 \\
Argillaceous sandstone & 9.62 & 9.88 & 10.21 & 10.33 & 10.01 & 9.21 & 1.71 \\
Coal & 1.66 & 1.72 & 1.68 & 1.75 & 1.70 & 1.72 & 9.98 \\
Silty sandstone & 10.45 & 9.76 & 9.57 & 10.53 & 10.26 & 9.29 & \\
\hline
\end{tabular}

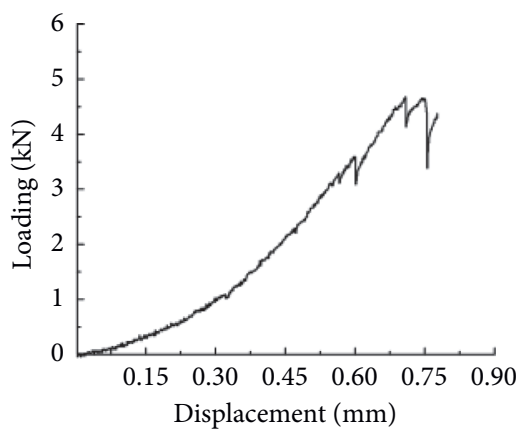

(a)

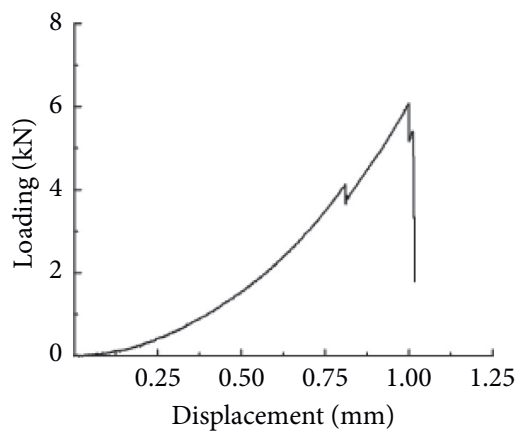

(b)

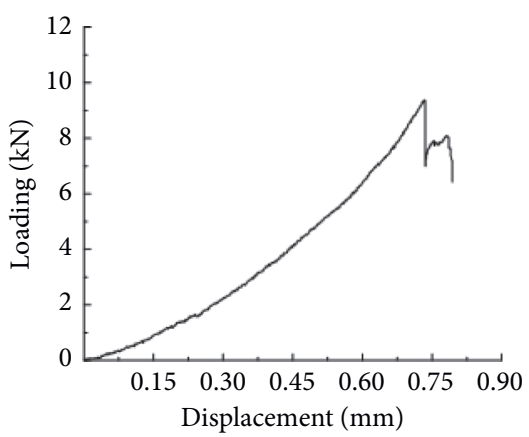

(c)

Figure 4: Typical curves of the Brazilian splitting test of some rock samples. (a) Argillaceous sandstone. (b) Coal. (c) Silty sandstone.

TABle 4: Tensile strength test of coal seam and roof rock samples.

\begin{tabular}{|c|c|c|c|c|c|c|c|}
\hline \multirow{2}{*}{ Rock stratum } & \multicolumn{6}{|c|}{ Serial number } & \multirow{2}{*}{ Average tensile strength $(\mathrm{MPa})$} \\
\hline & 1 & 2 & 3 & 4 & 5 & 6 & \\
\hline S1: argillaceous sandstone & 3.16 & 3.12 & 3.35 & 2.79 & 3.38 & 3.11 & 3.15 \\
\hline S2: coal & 1.21 & 1.53 & 1.38 & 1.66 & 1.82 & 1.76 & 1.56 \\
\hline S3: silty sandstone & 3.67 & 3.10 & 4.06 & 3.56 & 3.46 & 3.22 & 3.51 \\
\hline
\end{tabular}

TABLE 5: Classification of rock impact tendency.

\begin{tabular}{lccc}
\hline Category & I & II & III \\
\hline Impact tendency & No & Weak & Strong \\
Bending energy index $(\mathrm{kJ})$ & $U_{W Q S} \leq 15$ & $15<U_{W Q S} \leq 120$ & $U_{W Q S}>120$ \\
\hline
\end{tabular}


TABLE 6: Calculation and categories of the coal seam and rock roof impact tendency index.

\begin{tabular}{lcc}
\hline Rock stratum & Bending energy index $(\mathrm{kJ})$ & Impact tendency classification \\
\hline Argillaceous sandstone & 18.35 & II \\
Coal & 1.19 & I \\
Silty sandstone & 21.20 & II \\
Bending energy index & 40.74 & II \\
\hline
\end{tabular}

ratio of 0.25 , the homogeneity of 3 , the mesoaverage value of 70 , the strength reduction coefficient of 0.01 , and the element mesh number of $100 \times 100$. Moreover, Poisson's ratio and the elastic modulus of the element followed Weibull distribution, and the Mohr-coulomb failure criterion was adopted.

\subsection{Numerical Simulation Results}

5.4.1. Failure Characteristics with Different Sizes under Uniaxial Compression. In the process of uniaxial compression, when the height of the specimen is small, the whole specimen is constrained by the end effect, resulting in the end effect. With the increased size of the specimen, the central stress zone is close to the one-dimensional stress state, and the end effect is weakened. With the progress of the loading step, the friction or cracks between the particles in the rock gradually open. Furthermore, as the load increases, the cracks gradually expand, penetrate, and break from the left bottom to the middle. The small specimens are mainly transverse cracks and local shear failure, while the large ones belong to shear failure.

Figure 5 shows the uniaxial compression failure characteristics of specimens with different sizes. Figure 6 shows the cumulative number of acoustic emission loading steps of different-size specimens, and Figure 7 shows the characteristic curve of loading the step-stress-acoustic emission of differentsize specimens. The cumulative number of $\mathrm{AE}$ increases slowly at first, then increases rapidly with the increase in loading steps, and finally tends to a steady state. When the cumulative number of $\mathrm{AE}$ increases to a certain extent, the specimen size is severely destroyed. The AE characteristics of different sizes are similar. In Figure 7, AE has gone through three stages. Stable stage: AE signal is weak, mainly in the rock compaction stage, and small cracks and dense gaps are slowly squeezed and fused, so AE shows a weak signal. Slow-increase stage: with the increased load, the number of AES has an increasing trend, but on the whole, the early and middle periods of this stage are relatively stable, and the rising starting point of this stage takes longer mainly because the stress in this process is relatively small. Active stage: close to the peak stress, the AE signal is enhanced instantaneously. AE increases by leaps and bounds and becomes active intermittently because the original cracks develop and new cracks appear in the specimen with the increased load. There is an inflection point in the rising curve, indicating that the specimen is to show the signs of failure. When the specimen is damaged, the main crack runs through, and the specimen changes from whole to fragmented, resulting in a rapid decline in the bearing capacity of the specimen.
5.4.2. Relationship between Strength Characteristics and Bending Energy Index. The stress-strain curve in Figure 8 shows that the strength of the rock mass decreases with the increased specimen size, and the microcracks in the rock sample increase correspondingly. The increased heterogeneity caused by increased meso-defects is an essential reason for the size effect. The peak strength decreases with the increased size, and the rock failure changes from plastic to brittle failure. With the increased size, the strength of multiple groups of specimens tends to be increasingly stable. Furthermore, when the size range is larger, the strength of the specimens is maintained at a relatively stable value. Similarly, with the increased specimen size, the bending energy index decreases from sharply to slowly. The larger the specimen size is, the lower the bending energy index is (see Figure 9). When the specimen is broken, the stress-strain curve decreases sharply and AE also decreases significantly.

5.4.3. Failure Characteristics of Specimens under the Same Size and Different Surrounding Pressure. Each circle in the $\mathrm{AE}$ failure diagram represents a microfracture, that is, an $\mathrm{AE}$ event. The size of the circle represents the relative energy magnitude, which is proportional to the strength of the unit. Meanwhile, the white circle represents the shear failure; the red circle represents tensile failure; and the circle indicates the location of the AE event. From the simulation, the AE appears earlier under low confining pressure than under high confining pressure in the same period. With the increase in confining pressure, the time of the maximum frequency of $\mathrm{AE}$ of the rock is delayed continuously. The peak of the AE frequency is no longer corresponding to the stress-strain curve (Figure 8). The reason is that under low confining pressure, the strengthening effect of the specimen is weak with low shear and failure strength, so the AE activity is intense, and the backward phenomenon is not apparent. Under the high confining pressure, the lateral binding force of the rock is larger, with the closed pores in the rock. The strengthening effect of high confining pressure on the rock is strong. Therefore, the shear resistance and failure strength of the rock are high, and the generation of new cracks in the rock is restrained. There is a relative lag between the onset time of $\mathrm{AE}$ and the macroscopic failure time of rock. Figures 10 and 11 show the lateral pressure can prevent the microcrack from forming and developing in the specimen and make the specimen more uniform in macroscopic appearance. With the increased confining pressure, the stress field changes, in which the shear stress and the maximum principal stress gradually increase. The stress field concentrates on the top of the specimen, with the increased compressive strength and increased ultimate failure 

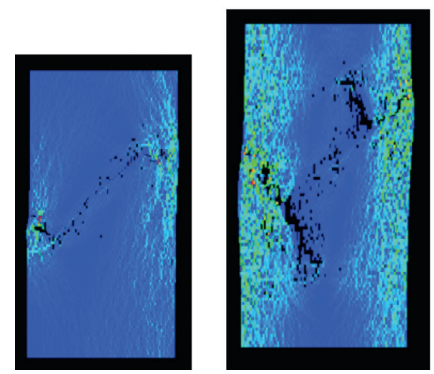

$50 \mathrm{~mm} \times 100 \mathrm{~mm}$

$75 \mathrm{~mm} \times 150 \mathrm{~mm}$

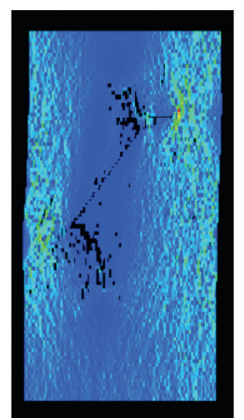

$100 \mathrm{~mm} \times 200 \mathrm{~mm}$

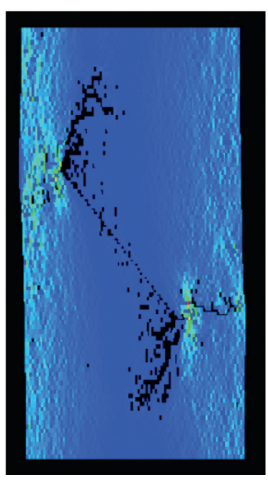

$150 \mathrm{~mm} \times 300 \mathrm{~mm}$

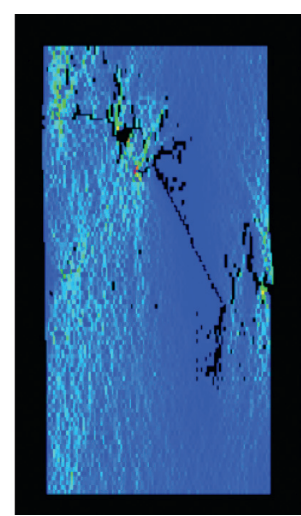

$200 \mathrm{~mm} \times 400 \mathrm{~mm}$

Figure 5: Typical failure of rock roof with different sizes in the uniaxial compression test.

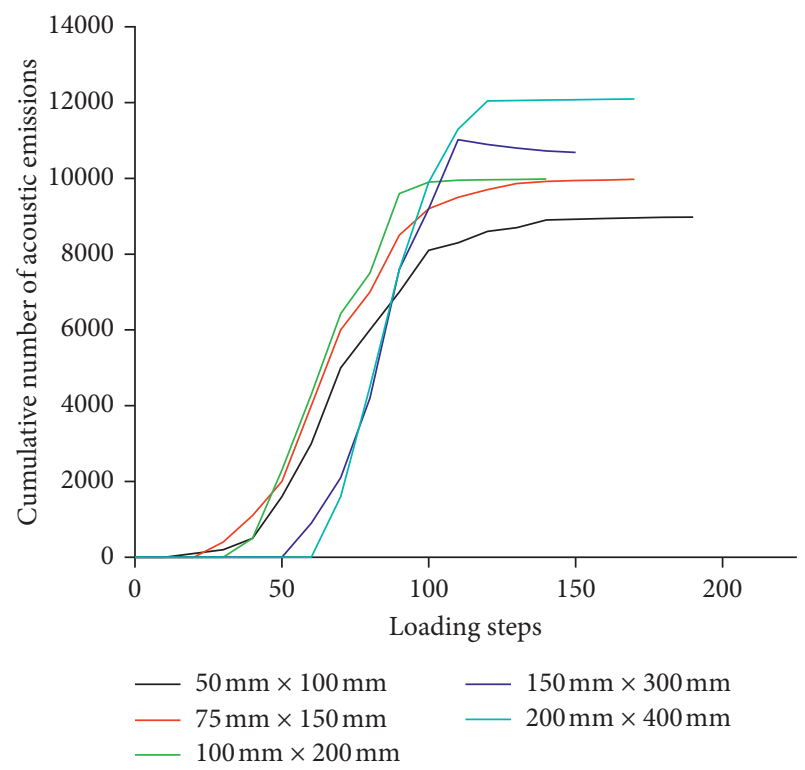

FIgURE 6: Cumulative number of AE-loading steps of rock roof with different sizes.

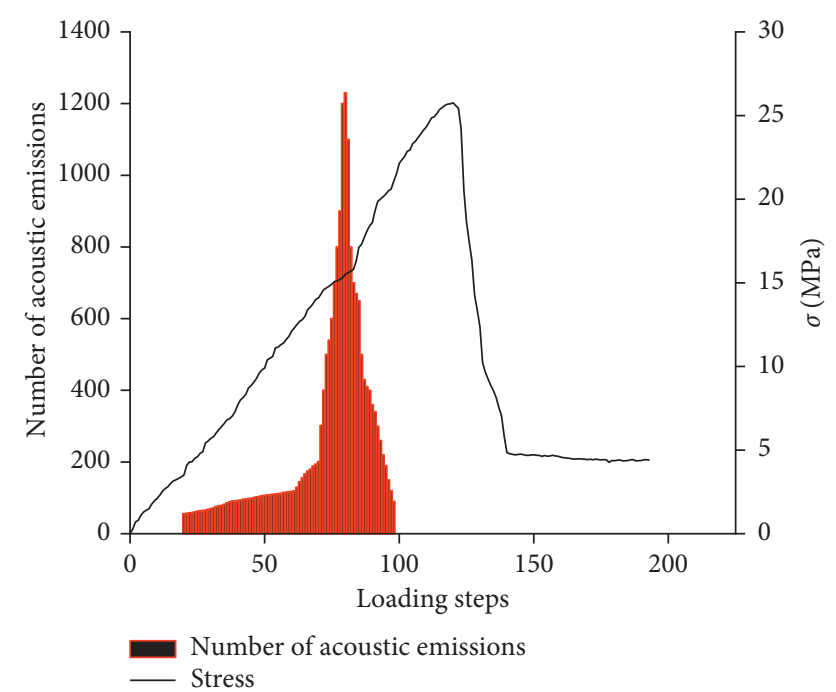

FIGURE 7: Step-stress-AE characteristic curve of rock roof with the different sizes.

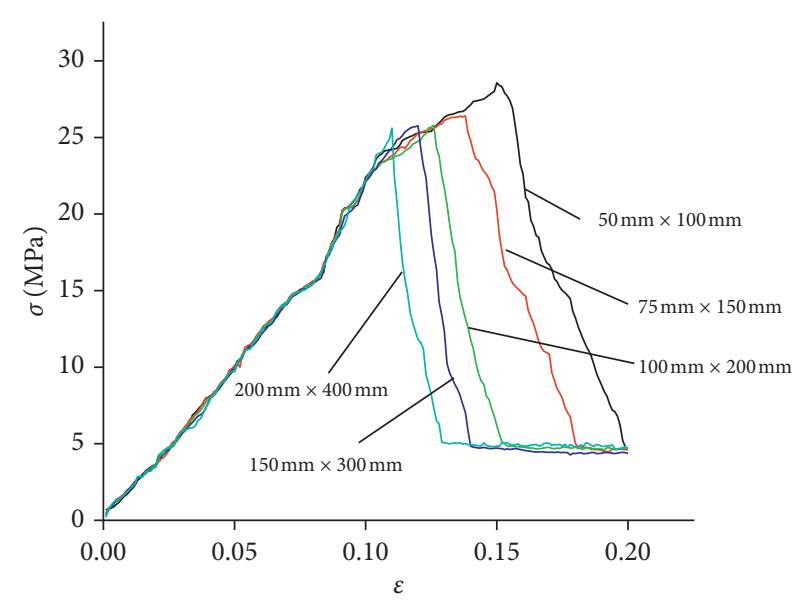

FIGURE 8: Stress-strain curves of rock roof of different sizes.

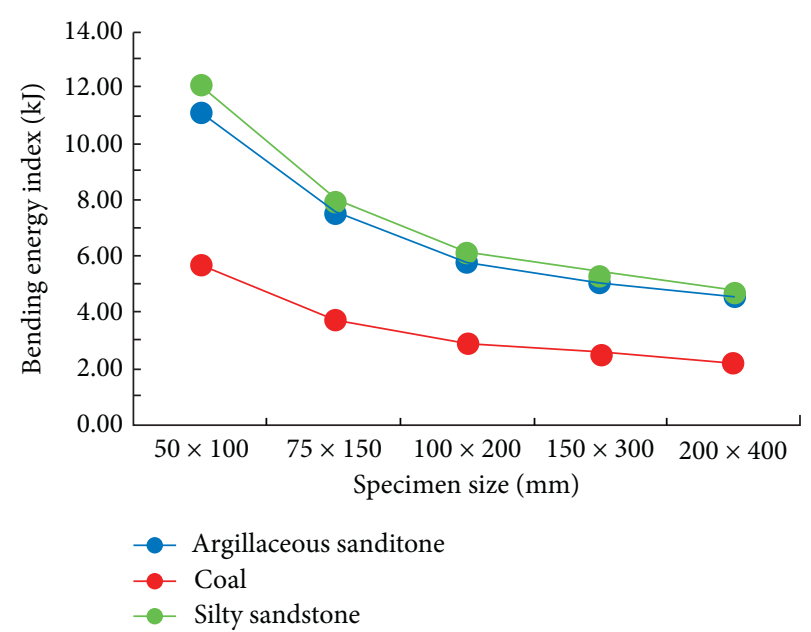

FIGURE 9: Failure relationship of the bending energy index with the increased rock roof size.

strength. When the distribution of microcracks is increasingly concentrated, the microcracks and the angle of the macrocrack surface increase gradually. The angle between the main crack-control surface and the maximum principal 


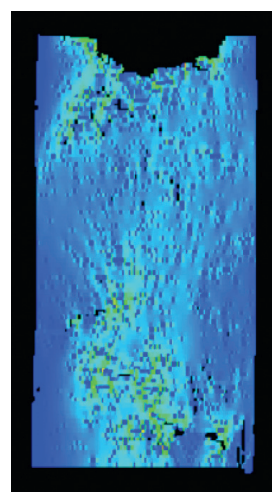

(a)

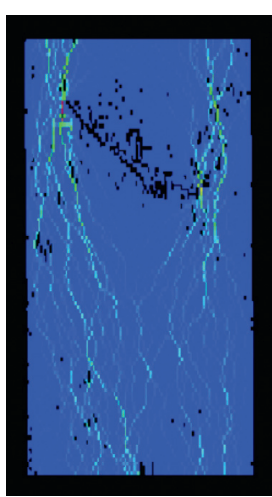

(b)

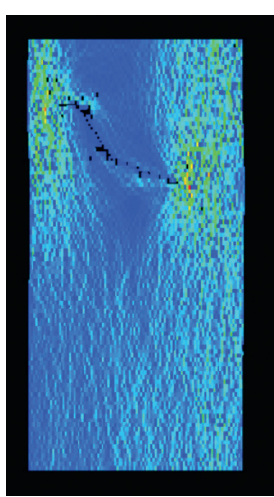

(c)

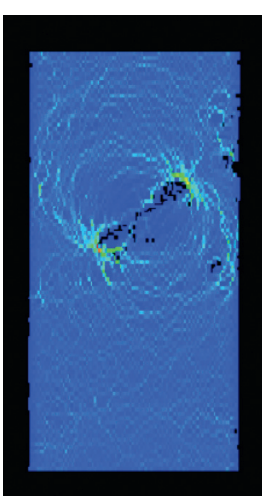

(d)

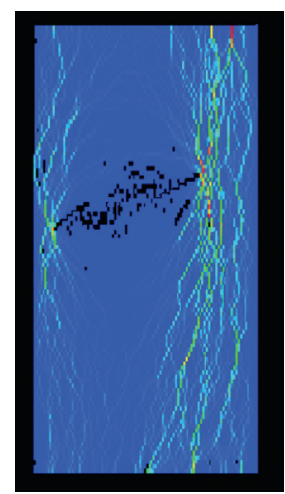

(e)

Figure 10: Typical failure of rock roof with the same size under different time steps: (a) $10 \mathrm{MPa}$, (b) $20 \mathrm{MPa}$, (c) $30 \mathrm{MPa}$, (d) $40 \mathrm{MPa}$, and (e) $50 \mathrm{MPa}$.

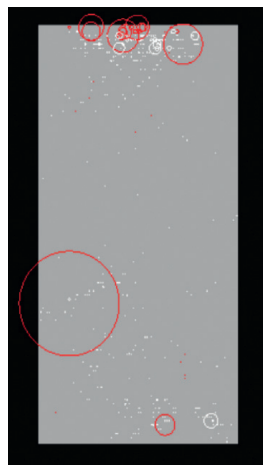

(a)

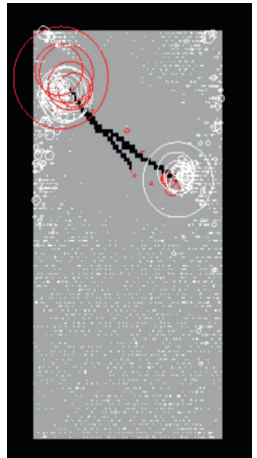

(b)

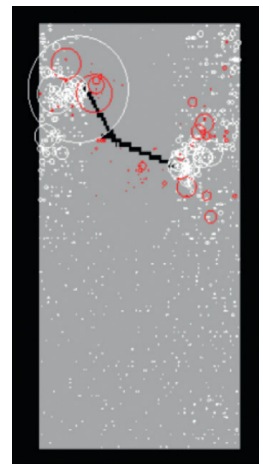

(c)

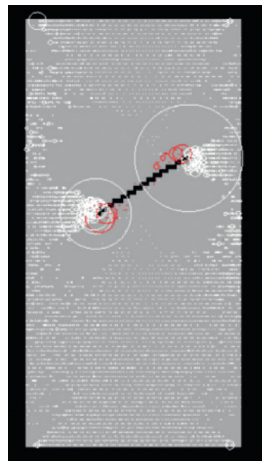

(d)

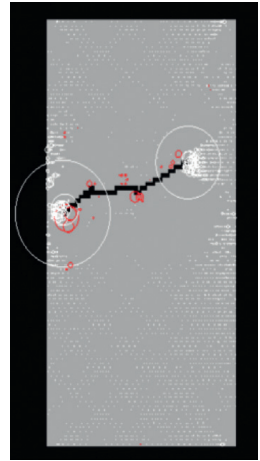

(e)

FIGURE 11: AE failure of the rock roof of the same size under the different time steps: (a) $10 \mathrm{MPa}$, (b) $20 \mathrm{MPa}$, (c) $30 \mathrm{MPa}$, (d) $40 \mathrm{MPa}$, and (e) $50 \mathrm{MPa}$.

stress increases gradually with the failure, transforming from tensile to shear failure.

\subsubsection{Relationship between Strength Characteristics and} Bending Energy Index under Different Confining Pressures. The stress-strain curve is shown in Figure 12; although the rock is subjected to confining pressure, the initial compaction, elasticity, plasticity, and postpeak failure can be reflected in the failure process of the rock under the confining pressure. Among them, the duration of the initial compaction stage and plastic stage is relatively short. With the increased confining pressure, these two stages become less and less obvious, indicating that rock deformation is suppressed under high confining pressure. The confining pressure effect is evident in this test, which shows that before rock failure, with the increased confining pressure, the elastic limit, deformation, and compressive strength are significantly improved. With the increased rock size, the postpeak brittleness of rock increases with the significant confining pressure of rock. The peak strength and peak strain of rock increase linearly, and the plastic deformation increases gradually. The failure morphology significantly changes with the peak strain, and the peak strength and residual strength gradually increase. However, when it is larger than this size range, the strength is maintained at a relatively stable value. Similarly, with the increase in the size, the bending energy index of the specimen increases from slowly to dramatically. Moreover, the higher the confining pressure is, the higher the bending energy index is, and it is shown in Figure 13.

\subsubsection{Relationship between Strength Characteristics and} Bending Energy Index under the Unloading. There are few $\mathrm{AE}$ events before unloading, and the $\mathrm{AE}$ events are mainly concentrated in the unloading stage, which is dominated by sudden and high-density energy release. When the rock is unloaded, the internal cracks suffer initiation, propagation, penetration, and sudden instability failure. Figure 14 shows that due to the different confining pressures, the fracture form of the unloaded is quite different from failure along the joint surface to the failure of the penetrating joint surface and finally to a certain angle between the fracture zone and the joint surface. Figure 15 shows that the stress of the sample changes with the loading step under five kinds of confining pressure unloading. When the stress value exceeds $80 \%$ of the peak strength, the curve shows a convex shape with the increase in strain, and the sample undergoes irreversible plastic deformation. When the 


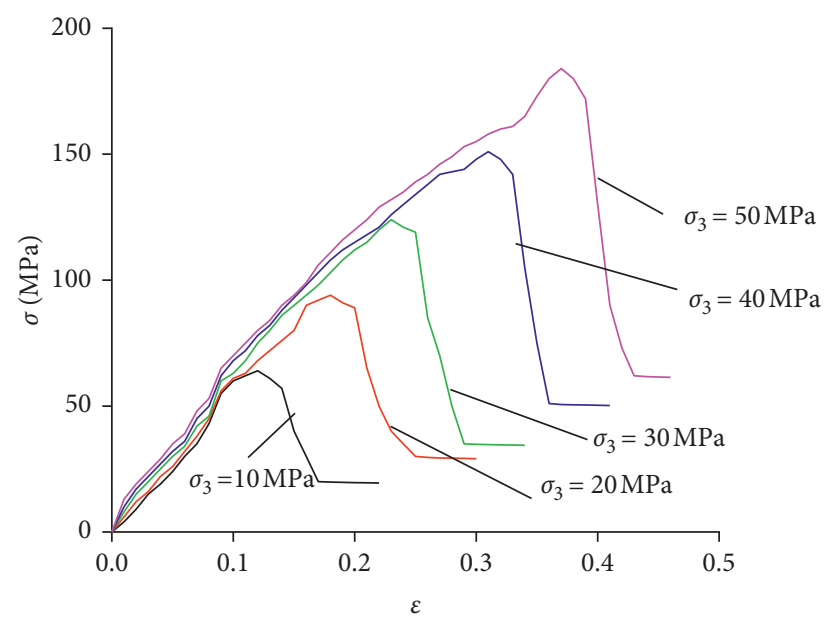

FIGURE 12: Stress-strain curves of rock roof under different confining pressures.

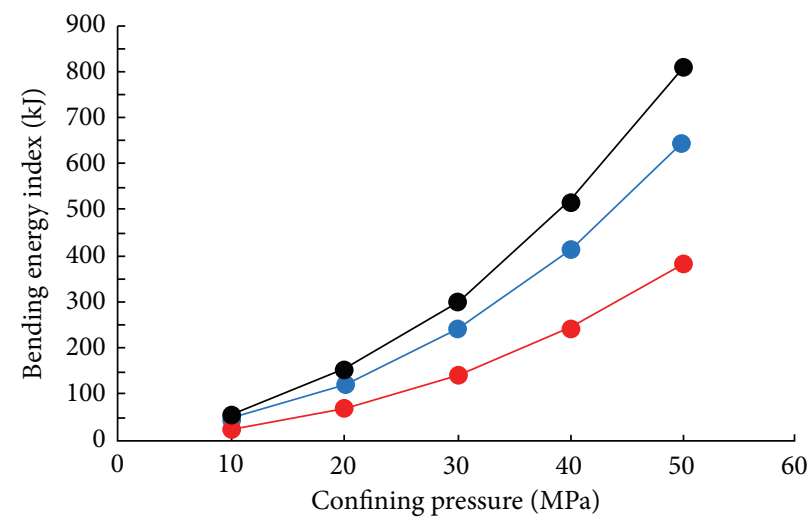

- Argillaceous sandstone

- Coal

- Silty sandstone

FIGURE 13: Relationship between the bending energy index and confining pressures under loading.

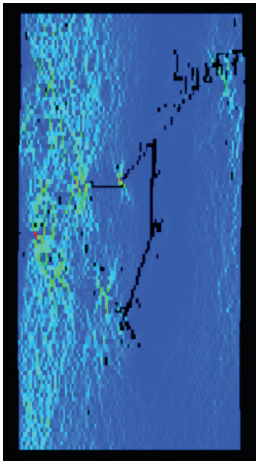

(a)

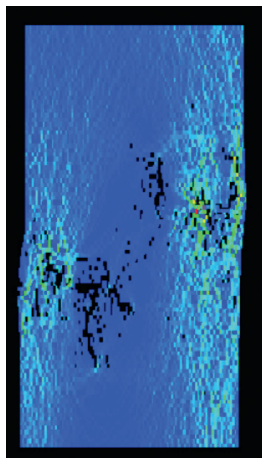

(b)

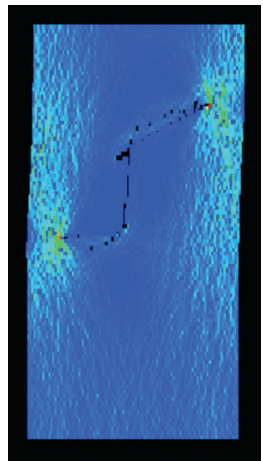

(c)

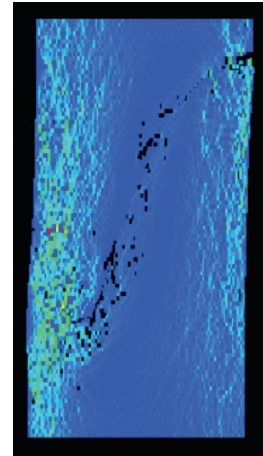

(d)

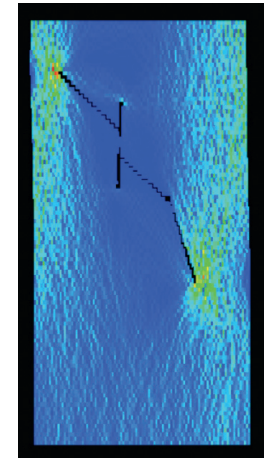

(e)

FIGURE 14: Failure of rock roof under the unloading with different confining pressures: (a) $10 \mathrm{MPa}$, (b) $20 \mathrm{MPa}$, (c) $30 \mathrm{MPa}$, (d) $40 \mathrm{MPa}$, and (e) $50 \mathrm{MPa}$.

stress exceeds the peak strength, the stress-strain curve shows a vertical drop, and the stress presents a "cliff-like" fall. The penetrating joints in the rock significantly weaken the compressive strength. When the bearing capacity is instantly reduced, the brittleness is more apparent with the sudden failure of the rock. Under the same conditions, the bending energy index produced by unloading (Figure 16) is much higher than that produced by loading (Figure 13), which is 


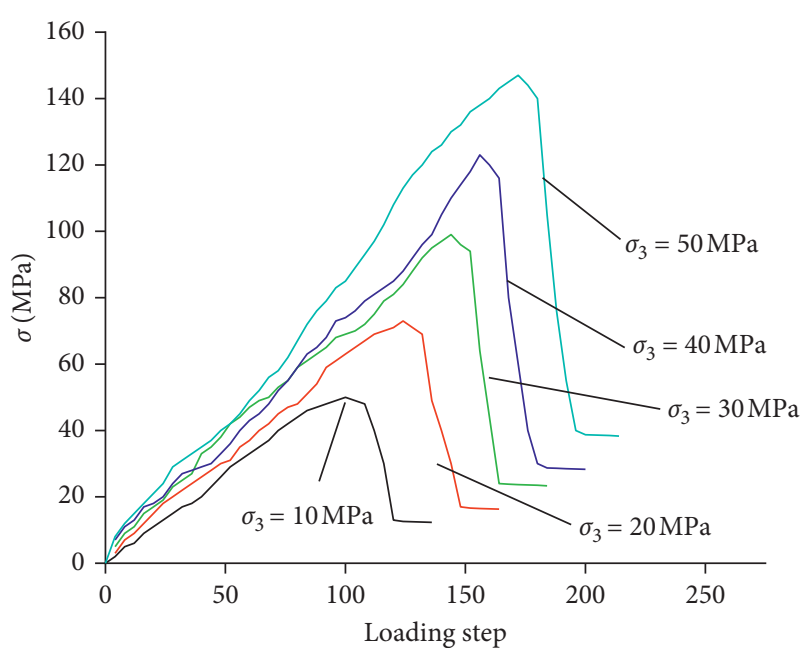

Figure 15: Stress and step curves of rock roof under different confining pressures.

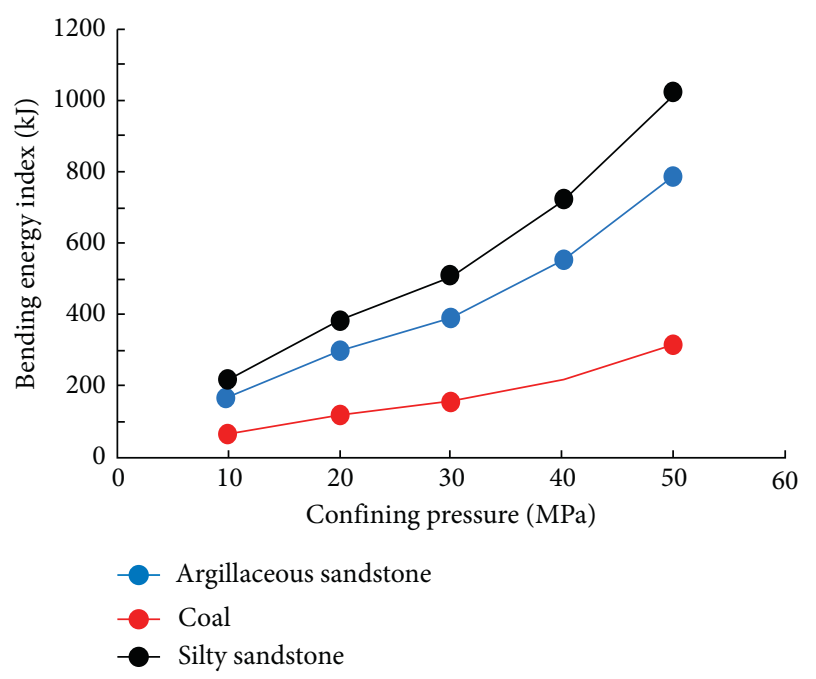

FIGURE 16: Relationship between bending energy index and confining pressures during unloading.

consistent with the phenomenon of rock burst in the coal and rock mass in practical engineering. It indicates that rock burst is more likely to occur after excavation and unloading due to the joints.

\section{Conclusion}

Through laboratory mechanical tests and numerical simulation tests with RFPA $^{2 \mathrm{D}}$ software, the work studied the impact tendency of the rock roof and coal, as well as the failure characteristics and laws of rock roof under loading and unloading of different sizes and confining pressures. The main conclusions are as follows:

(1) Through laboratory mechanical tests, the bending energy index of argillaceous sandstone was $18.35 \mathrm{~kJ}$; that of coal was $1.19 \mathrm{~kJ}$; and that of silty sandstone was $21.20 \mathrm{~kJ}$; the bending energy index of the composite roof was $40.74 \mathrm{~kJ}$. According to the classification standard, the coal had no impact tendency, and the argillaceous sandstone, silty sandstone, and composite roof all had weak impact tendency, which indicated that the whole roof strata had weak impact tendency.

(2) According to the uniaxial compressive strength test with different scales, the strength of rock mass decreased with the increase in the rock mass size. When the rock mass size increased to a specific size, the strength of rock mass increased slowly.

(3) Triaxial loading and unloading were tested for the same size under the action of different surrounding rocks. Under the same loading conditions, the strength and bending energy index of rock mass increased correspondingly with the increased surrounding rock, and the failure form of rock mass changed from tensile failure to shear failure. The failure form and strength characteristic of rock under unloading condition are different from that under loading condition, with more intense failure and higher bending energy index. Compared with the loading situation, the impact tendency of the unloading mode was higher, and it was prone to affect dynamic disasters. In the process of coal mining, the coal and rock mass were unloaded. The unloading test explained the physical phenomenon of the impact disaster of the coal and rock mass, which was more reasonable than using the indoor compression test to determine the impact tendency of the coal and rock mass.

\section{Data Availability}

No data were used to support this study.

\section{Conflicts of Interest}

The authors declare that they have no conflicts of interest.

\section{Acknowledgments}

This work was supported by the National Natural Science Foundation of China (51934003 and 51864023) and the project of scientific and technological innovation team support for the development of resources in Yunnan Province.

\section{References}

[1] C.-P. Lu, G.-J. Liu, Y. Liu, N. Zhang, J.-H. Xue, and L. Zhang, "Microseismic multi-parameter characteristics of rockburst hazard induced by hard roof fall and high stress concentration," International Journal of Rock Mechanics and Mining Sciences, vol. 76, pp. 18-32, 2015.

[2] P. K. Kaiser and M. Cai, "Design of rock support system under rockburst condition," Journal of Rock Mechanics and Geotechnical Engineering, vol. 4, no. 3, pp. 215-227, 2012. 
[3] W. Guo, Q. Gu, Y. Tan, and S. Hu, "Case studies of rock bursts in tectonic areas with facies change," Energies, vol. 12, no. 7, p. 1330, 2019.

[4] J. Zhou, X. Li, and H. S. Mitri, "Evaluation method of rockburst: state-of-the-art literature review," Tunnelling and Underground Space Technology, vol. 81, pp. 632-659, 2018.

[5] E. Y. Wang, J. J. Feng, Q. M. Zhang, X. G. Kong, and X. F. Liu, "Mechanism of rockburst under stress wave in mining space," Journal of China Coal Society, vol. 45, no. 1, pp. 100-110, 2020.

[6] M. C. He, H. P. Xie, S. P. Peng, and Y. D. Jiang, "Study on rock mechanics in deep mining engineering," Chinese Journal of Rock Mechanics and Engineering, vol. 16, pp. 2803-2813, 2005.

[7] A. Mazaira and P. Konicek, "Intense rockburst impacts in deep underground construction and their prevention," $\mathrm{Ca}$ nadian Geotechnical Journal, vol. 52, no. 10, pp. 1426-1439, 2015.

[8] Q. X. Qi, Y. Z. Li, S. K. Zhao et al., "Seventy years of development of coal mine rockburst in China: establishment and consideration of theory and technology system," Coal Science and Technology, vol. 47, no. 9, pp. 1-40, 2019.

[9] L. C. Dai, B. Wang, and K. Wang, "The impact tendency evaluation of coal mine and rock based on fuzzy clustering method," Advanced Materials Research, vol. 926-930, pp. 3653-3656, 2014.

[10] W.-Y. Guo, T.-B. Zhao, Y.-L. Tan, F.-H. Yu, S.-C. Hu, and F.-Q. Yang, "Progressive mitigation method of rock bursts under complicated geological conditions," International Journal of Rock Mechanics and Mining Sciences, vol. 96, pp. 11-22, 2017.

[11] Y. S. Pan, Y. Yang, H. Luo, Z. H. Li, and X. J. Zhu, "Experimental study on the mechanical charge induction law of the coal bumping proneness," Journal of Safety and Environment, vol. 18, no. 1, pp. 119-123, 2018.

[12] F. Gong, J. Yan, X. Li, and S. Luo, "A peak-strength strain energy storage index for rock burst proneness of rock materials," International Journal of Rock Mechanics and Mining Sciences, vol. 117, pp. 76-89, 2019.

[13] C. D. Su, R. F. Yuan, and X. X. Zhai, "Experimental research on bursting liability index of coal samples of Chengiiao coal mine," Chinese Journal of Rock Mechanics and Engineering, vol. 32, no. s2, pp. 3696-3704, 2013.

[14] T.-H. Ma, C.-A. Tang, S.-B. Tang et al., "Rockburst mechanism and prediction based on microseismic monitoring," International Journal of Rock Mechanics and Mining Sciences, vol. 110, pp. 177-188, 2018.

[15] L. M. Dou, C. P. Lu, Z. L. Mou, X. T. Zhang, and Z. H. Li, "Rock burst tendency of coal-rock combinations sample," Journal of Mining and Safety Engineering, vol. 23, no. 1, pp. 43-46, 2006.

[16] J. M. Yao, Y. Y. Yan, S. Z. Li, J. W. Yao, and X. Wang, "Damage index of coal seam rock burst proneness," Journal of China Coal Society, vol. 36, no. 2, pp. 353-357, 2011.

[17] Z. G. Lu, W. J. Ju, H. Wang et al., "Experimental study on anisotropic characteristics of impact tendency and failure model of hard coal," Chinese Journal of Rock Mechanics and Engineering, vol. 38, no. 4, pp. 757-768, 2019.

[18] F. Q. Gong, H. Ye, and Y. Luo, "Rate effect on the burst tendency of coal-rock combined body under low loading rate range," Journal of China Coal Society, vol. 42, no. 11, pp. 2852-2860, 2017.

[19] C. Wang, Y. F. Li, C. L. Zhang, L. Liu, and X. C. Huang, "Study on influence of indicator dimensionless on classification model of coal's bursting liability," China Safety Science Journal, vol. 29, no. 11, pp. 20-25, 2019.
[20] Methods for Determining the Physical and Mechanical Properties of Coal and Rock-Part 10: Methods for Determining Tensile Strength of Coal and Rock, GB/T 23561.102010.

[21] Methods for Determining the Physical and Mechanical Properties of Coal and Rock-Part 7: Methods for Determining the Uniaxial Compressive Strength and Counting Softening Coefficient, GB/T 23561.7-2009.

[22] R. Kong, X.-T. Feng, X. Zhang, and C. Yang, "Study on crack initiation and damage stress in sandstone under true triaxial compression," International Journal of Rock Mechanics and Mining Sciences, vol. 106, pp. 117-123, 2018.

[23] Methods for Test, Monitoring and Prevention of Rock Burst-Part 1: Classification and Laboratory Test Method on Bursting Liability of Roof Strata, GB/T 25217.1-2010.

[24] W. C. Zhu, C. A. Tang, T. H. Yang, and Z. C. Liang, "Constitutive relationship of mesoscopic elements used in RFPA2D and its validations," Journal of Rock Mechanics and Engineering, vol. 22, no. 1, pp. 24-29, 2003.

[25] S. Li, X. Y. Jiang, and C. Yang, "Numerical simulation of composite local flexural rock mass based on RFPA ${ }^{2 \mathrm{D}}$," Journal of Safety Science and Technology, vol. 16, no. 6, pp. 11-15, 2020.

[26] C. Wu, F. Gong, and Y. Luo, "A new quantitative method to identify the crack damage stress of rock using AE detection parameters," Bulletin of Engineering Geology and the Environment, vol. 27, no. 7, pp. 24-36, 2020.

[27] C. A. Tang and W. Zhao, "RFPA ${ }^{2 \mathrm{D}}$ system rock failure process analysis," Chinese Journal of Rock Mechanics and Engineering, vol. 16, no. 5, pp. 109-110, 1997. 